\title{
Escrituras de Nueva York: geometría urbana y metamorfosis poéticas
}

\author{
Celia DE ALDAMA ORdóÑEZ \\ Departamento de Filología Española IV \\ Universidad Complutense de Madrid \\ celia_aldama@hotmail.com
}

Recibido: $21 / 12 / 2012$

Modificado: $10 / 04 / 2013$

Aceptado: 05/06/2013

\section{Resumen}

A partir de tres exponentes de la poesía hispanoamericana y con el propósito de reflexionar en torno a la naturaleza inestable de la realidad urbana, que va mudando en función de sus relatores, examinaremos la obra de Concha Zardoya, Eduardo Mitre y Enrique Lihn. Todos ellos escriben a partir de Manhattan para reelaborar, una vez más, la imagen literaria de la megalópolis que, si a principios de la centuria es ovacionada como símbolo del progreso, a finales de siglo, se maneja como prueba irrefutable del fracasado mito de la modernidad.

Palabras clave: Nueva York, espacio urbano, poesía hispanoamericana, posmodernidad.

Title: New York's writings: urban geometry and poetic metamorphosis Abstract

Taking different exponents of Latin American poetry as a starting point and trying to demonstrate the unstable nature of the urban reality, changing with the voice of each of its narrators, we will deeply examine the work of three poets, Concha Zardoya, Eduardo Mitre and Enrique Lihn. All of them will provide evidence of their passage through New York city which, even if acclaimed at some point as a symbol of progress, at the end of the century has been shown as an unmistakable sign of the unsuccessful myth of modernity.

Keywords: New York, urban space, Hispano-American poetry, postmodernity.

\section{Índice}

1. Introducción

2. Nueva York y sus relatores: tres cartografías lírico-citadinas

2.1. Concha Zardoya: la lectura icariana de un no lugar

2.2. Eduardo Mitre: la experiencia del exilio en la cárcel-ciudad

2.3. Enrique Lihn: voces de margen o arrabal

3. El mudar de las imágenes en el discurso poético urbano 


\section{Introducción}

La ciudad goza de una presencia apabullante en el mundo de las letras modernas, que encuentran en ella, debido a su potencial estético y densidad semántica, un extenso y fructífero campo tanto de creación como de estudio. Las ciudades son reelaboradas incansablemente por parte de los escritores que, valiéndose del medio literario, participan en la construcción de mitologías urbanas, esto es, de imperecederos espacios aglutinantes donde se codifican, entreveradas en la ficción de los relatos, las denominadas por Raymond Williams "estructuras del sentimiento" de cada época. Desde el París de Baudelaire, el Londres de Dickens o el San Petersburgo de Dostoievski hasta el Dublín de Joyce, la Alejandría de Lawrence Durrell o el Buenos Aires de Arlt y Borges, asistimos a la conversión del espacio citadino en un topos literario que se erige, ya desde el siglo XIX, como referente colosal para la comprensión del pathos y del pensamiento modernos.

Tal y como señala Dionisio Cañas en su exhaustivo estudio El poeta y la ciudad, el arranque del diálogo entre la poesía hispanoamericana y la urbe neoyorkina se produce en el poemario Versos Libres de José Martí (Cañas 1994: 158). A partir de este momento, en que Nueva York irrumpe en el universo poético del continente latinoamericano, su identidad como objeto textual va a sufrir radicales alteraciones. Su forma literaria asume distintas siluetas en función de las connotaciones que, en cada época, le asignen sus relatores; mientras Rubén Darío, en su poema "La gran cosmópolis", refleja la barbarie que subyuga a su población, el peruano Carlos Oquendo de Amat aprovecha la potencialidad vanguardista de sus arriesgadas edificaciones para construir su poema "newyork". En cambio, más avanzado el siglo, los nombres de dos rivales chilenos, Pablo Neruda y Pablo de Rokha, destacarán en el proceso de aniquilación del mito neoyorkino, al convertir la ciudad en expresión descarnada del imperialismo yankee.

Tal exuberancia de formas citadinas en el universo cultural contemporáneo ha estimulado nuestro acercamiento a los poemarios de tres creadores hispanoamericanos -Concha Zardoya, Eduardo Mitre y Enrique Lihn- que, a pesar de notables diferencias en su estética, en las condiciones biográficas de su labor intelectual y en su grado de popularidad dentro de la tradición occidental, enfrentan un mismo escenario urbano y lo convierten en sujeto protagonista de su elaboración poética.

El análisis de los textos partirá del postulado semiológico de Roland Barthes según el cual la noción de ciudad debe entenderse como espacio significante construido a partir de signos descifrables. Sin embargo, nuestra lectura de la urbe, concebida por el erudito francés como un "discurso, una escritura, una inscripción del hombre en el espacio" (Barthes 1993: 259), se verá enrevesada por la 
intermediación de otro tipo de material textual: el poema. Así, y mediante el recorrido por las distintas propuestas de escritura, intentaremos desbrozar la realidad literaria de la metrópolis neoyorkina que, al desmembrarse en múltiples y variadas imágenes refractarias de sí misma, nos ofrece distintas versiones que no solo se complementan, sino que llegan incluso a contradecirse.

De modo que el papel cada vez más indispensable que cobra la ciudad como objeto de estudio en distintas disciplinas científicas, en general, sumado a la inexistencia de un pormenorizado análisis dedicado a explorar la relación entre la capital estadounidense y el campo literario de América Latina, en particular, motivan nuestra iniciativa de trabajo que, en su proceder comparado, pretende desvelar las peculiaridades estéticas e ideológicas que surgen del acercamiento entre universos materiales y simbólicos tan dispares.

\section{Nueva York y sus relatores: tres cartografías lírico-citadinas}

Antes de entrar a considerar los textos escogidos y de reflexionar alrededor de las perturbaciones que sufre la morfología literaria de la ciudad de Nueva York a lo largo de los mismos, nos adentraremos en un periodo histórico especialmente controvertido que suele identificarse con el problemático nombre de posmodernidad. Los siguientes tres poemarios elegidos se redactan después de la fecha simbólica del 16 de marzo de 1972, momento emblemático en el que, según la cronología trazada por el arquitecto estadounidense Charles Jencks, debe situarse la muerte de la modernidad ${ }^{1}$. No olvidaremos, sin embargo, que la operatividad de este nuevo marco conceptual, forjado desde el "centro" y asociado a la crisis epistemológica experimentada en las sociedades occidentales, resulta limitada a la hora de interpretar las creaciones que se generan en geografías "periféricas"2.

Sin embargo, nuestro caso es particularmente sugestivo dado que Zardoya, Mitre y Lihn enfrentan un espacio que, en las últimas décadas del siglo $\mathrm{XX}$, se yergue como el paradigma de la ciudad fragmentada y discontinua del mundo posmoderno. La fisionomía de la urbe neoyorkina parece desvincularse de su referente material más

${ }^{1}$ En el título La posmodernidad, J. F. Lyotard recupera la emblemática fecha del 16 de marzo de 1972 que, marcada por Charles Jencks, figura desde entonces como data fundacional de un nuevo tiempo posmoderno. En el día señalado, se lleva a cabo la demolición de un barrio de la arquitectura moderna que formaba parte de un gran proyecto urbanístico desarrollado en la ciudad de San Luis, Estados Unidos, en los años 1954 y 1955 (Lyotard 1994: 11).

2 Por poner un ejemplo, sería necesario preguntarse si las teorías de J. F. Lyotard, acerca de la aniquilación de los metarrelatos y la imposibilidad de comprender los hechos de forma absoluta, son compatibles y aplicables a los contextos hispanoamericanos, cuya condición liminal y "subdesarrollada" conlleva una actitud distinta con respecto a las conquistas y los fracasos del hombre moderno. 
inmediato, así como de sus pretéritas versiones imaginarias, para transmutarse en un estado existencial, la devastada alegoría de un mundo insatisfecho y sometido a derrumbamientos constantes donde el hombre, anónimo y desencantado, camina sin rumbo, trazando trayectorias circulares o laberínticas. Sus habitantes se mueven en un terreno quebradizo, entre arquitecturas móviles y satelitales que corroboran la componente "irracional" (Koolhaas 2009: 9) e "insensata" (Le Corbusier 1985: 116) de la metrópolis.

Junto a tales premisas, nuestro trabajo se sustenta sobre una fuerte convicción acerca del potencial cartográfico de la poesía urbana; así como los mapas han registrado el estrepitoso desarrollo de las ciudades y se constituyen como fuente clave para la reconstrucción de su historia urbana, las cartografías poéticas no solamente capturan la imagen citadina, sino que participan en su construcción 0 , por lo menos, en la de la imagen que la gente tiene de ellas. Sin embargo, frente a la objetividad del cálculo y el trazado geométrico, el mapa del poeta, al componerse de materia alfabética connotada ideológicamente, es relativo y oscilante. Hemos aquí una sustancial diferencia que hará de cada poemario un objeto intransferible y que, a pesar de coincidir en su referente extratextual, exhibirá notables diferencias y particularismos. De nuestro viaje a través de los sucesivos retratos de la urbe obtendremos información heterogénea y desordenada que, al sedimentarse en nuestro imaginario, logrará construir una nueva imagen provisional de Nueva York tan efímera e irreal como las anteriores.

\subsection{Concha Zardoya: la lectura icariana de un no lugar}

Concha Zardoya (1914-2004), hija de inmigrantes españoles, publica el título Manhattan y otras latitudes en España en el año 1983. El poemario se divide en dos secciones, de las cuales la primera está dedicada de manera íntegra a describir la ciudad neoyorkina mientras que en la segunda se hilvanan los recuerdos de distintas ciudades norteamericanas y españolas en las que vivió la autora a lo largo de su vida. Desde el comienzo, la voz del sujeto lírico adopta la óptica de una transeúnte que recorre, como curiosa viajera de paso, los caminos de Manhattan. El espacio inicial que se nos presenta en el primer poema, "He bajado del aire", es el aeropuerto Kennedy, que responde a la categoría de no lugar establecida por Marc Augé como la paradigmática de la sobremodernidad. Por oposición al concepto sociológico de lugar, los no lugares son identificados con "las instalaciones necesarias para la circulación articulada de personas y bienes, los medios de transporte mismos o los grandes centros comerciales [...]. Son lo contrario de la utopía: existen y no postulan ninguna sociedad orgánica" (Augé 1995: 41). Zardoya, al aterrizar en suelo americano, describe la "falsa luz endurecida" que antecede la visión del nuevo mundo cuyas primeras impresiones son plasmadas 
en el poema "Paisaje neoyorkino". En este, la megalópolis es descrita como un universo computacional donde "sumas de sumas álzanse y ascienden", un escenario de dinamismo asimilable al de los movimientos del mercado financiero, marcados por gráficos expectantes de las subidas o caídas del dólar. Se despliega una espantosa visión del contexto urbano que, lejos de exaltar la majestuosidad y ostentación de sus edificios, los degrada a un amontonamiento de torres de cemento, un sinfín de "perforadas columnas de granito". La mirada icariana de la autora planea sobre la superficie, se eleva hasta alcanzar una perspectiva aérea, tradicionalmente denominada "vista de vuelo de pájaro", y desde ella denuncia la absoluta sumisión de la naturaleza al poder triturador de las (de)construcciones humanas:

Son nuevas cordilleras: sus tentáculos,

Desnudos, agresivos, rectamente,

Golpean o destrenzan libres nubes. (Zardoya 1983: 12)

Este paisaje, en el que una tupida filigrana de acero entorpece la contemplación del cielo, impacta hondamente a nuestra poeta, cuyo ojo, como mecanismo de resistencia y redención frente a tal nefasto espectáculo, "desordena la armonía / soñando cataclismos y volcanes". La elaboración literaria que hace la autora de la retícula urbana guarda algunas coincidencias con la extravagante hipótesis que Rem Koolhaas defiende en su Manifiesto retroactivo para Manhattan, según la cual la ciudad se proyecta como "fábrica de experiencia artificial donde lo real y lo natural dejan de existir" (Koolhaas 2009: 9). Para el arquitecto holandés, el trazado hipodámico de sus calles anuncia que "el sometimiento de la naturaleza, por no decir su extinción, es su verdadera ambición" (Koolhaas 2009: 20). Asimismo, en distintos poemas de Zardoya, se denuncia la violenta invasión de lo "sintético irresistible" (Koolhaas 2009: 23) que se impone, con cada vez más brutalidad, sobre un tejido urbano sometido a constantes remodelaciones, a una cultura abrasiva de construcción y destrucción que impide al urbanita entrar en contacto con un extinguido medio natural.

Enlazamos así con uno de los tópicos más sonados de la ciudad neoyorkina, que la vincula directamente con la sacralización del valor monetario que caracteriza el mundo capitalista. En el poema "En esta gran ciudad hay catedrales", el dólar se presenta como el implacable y todopoderoso sustituto de antiguos dioses y mitologías. El poder económico se transforma en el eje gravitacional en torno al cual orbitan todos los habitantes de la urbe, generando, como diría Max Weber, una "jaula de hierro" o, en palabras de Marshall Berman, un "orden inexorable, legalista y burocrático que determina la vida de los 
individuos nacidos dentro del mecanismo con una fuerza irresistible" (Berman 1999: 14):

En esta gran ciudad hay catedrales

En que se adora a un Dios: al Rey Dinero.

Las ceremonias son rituales sumas,

Rituales restas, cifras fabulosas

Que suben o que bajan a capricho

De Papas- Empresarios- Chambelanes

Del ciego Dios que mueve sus acciones. (Zardoya 1983: 13)

La combinación de los campos léxicos de la economía y la religión le sirve a Zardoya para demostrar cómo la Bolsa de Wall Street se ha convertido en un lugar sacro, pontificado y reverenciado, donde el juego de los accionistas, los balances de pérdidas y ganancias y el febril ritmo de las inversiones han acelerado la demolición del resto de los credos. Las críticas de la poeta se dirigen ferozmente a los efectos inadvertidos de una especulación desmesurada que, por otra parte, se muestra ciega y desnuda de escrúpulos ante la humanidad que late, herida, bajo los números ("Nunca hay hombres debajo de los ceros, / ni hambrientos niños debajo de los unos. / Ni una sola conciencia que pregunte, / recata sus angustias bajo un siete / ni el temor de matar bajo los cinco"). De manera simultánea, los nuevos mitos del imperio tecnológico, "televisiones, radios, teléfonos", embriagan y subyugan a un mundo acartonado donde el espíritu calculador del hombre se ve condicionado, según George Simmel, por una economía monetaria "que ha llenado la vida con el sopesar, el calcular, el determinar conforme a números y el reducir valores cualitativos a cuantitativos" (Simmel 1986: 250).

Otro espacio especialmente evocador para los tres poetas será el metro, universo subterráneo que aparece retratado como lugar infernal, asfixiante y vertiginoso en el poema "Subway". En este, se da forma poética a dos tópicos que atraviesan toda reflexión en torno al hombre contemporáneo: en primer lugar, la extrema presunción que le lleva a conquistar todo recoveco terrestre evitando que quede algún lugar sin explorar, socavar o demoler. Zardoya recuerda cómo "el hierro penetra en los abismos / en la roca horadada, en esos pozos / que minan la ciudad y la sostienen". En segundo lugar, se ponen de manifiesto cuestiones relacionadas con la alienación del urbanita, su nulidad existencial, su verse reducido a categoría numérica, su insularidad y aislamiento en un mundo de mónadas falsamente libres. En el poema, los hombres desfilan en un anonimato informe y obstinado, "de nicho en nicho", "de tumba en tumba"; son seres enajenados que se dejan llevar por túneles infinitos a un destino tedioso y enajenante: la oficina, la fábrica, el 
centro comercial. Esta sociedad urbana, descrita como enorme engranaje de piezas amorfas donde el individuo es intercambiable por un "robot, clavija, biela o torniquete", se contrapone al paisaje rural "donde el hombre se sabe que es un hombre, / entre vides y trigos y olivares".

Finalmente, la autora, después de planear macroscópicamente sobre las superficies metropolitanas, desciende y ahonda en aspectos microscópicos como las figuras individuales de artistas y pensadores norteamericanos. Las últimas piezas de la sección dedicada a Manhattan encadenan una serie de elogios dirigidos a personajes de la talla de Walt Whitman cuya presencia aún perturba las calles de la ciudad. Otros poemas se dedican a reproducir memorables obras de arte de Velázquez, Picasso o Kandinsky que se encuentran coleccionadas en el Metropolitan Museum of Art. Esta tendencia a la hibridación genérica, señalada por Lozano Mijares como característica paradigmática de la novela posmoderna española ${ }^{3}$, estará igualmente arraigada en los siguientes poetas, donde percibimos la voluntad de ensartar la voz literaria con el lenguaje pictórico, cinematográfico o musical. Un rasgo compartido por los tres textos en análisis es justamente esta inclinación por el intercambio de formas y la consiguiente disolución de las fronteras que aíslan disciplinas en principio ajenas. De manera coincidente a Marshall Berman, que utiliza la metáfora de la perfecta y natural continuidad entre los tres posibles estados de la materia para explicar la constante fluctuación que caracteriza toda manifestación del mundo moderno (Berman 1999: 2), nuestros autores insisten en la posibilidad de convertir, con idéntica naturalidad, el trazo en letra o la nota musical en escritura silábica.

\subsection{Eduardo Mitre: la experiencia del exilio en la cárcel-ciudad}

Para enlazar con el apartado anterior, tomaremos como ejemplo el poema "Con Edward Hopper", donde Eduardo Mitre (Bolivia, 1943) poetiza una escena del pintor como intento por demostrar la posible correspondencia entre las artes, esto es, las afinidades del texto verbal y el plástico que cooperan en muchos de sus propósitos. De este modo, a lo largo de su poemario, Manhattan aparecerá como una realidad inestable, polivalente y proteica, construida a partir de

\footnotetext{
${ }^{3}$ A pesar de que el análisis de Lozano Mijares se focalice sobre el género novelístico en España, es posible extrapolar algunas de las características que la autora propone como representativas de la novela posmoderna española, dado que funcionan en otros contextos literarios. Entre las tendencias que confirman una sintomatología común en ambas escrituras, destacan: la hibridación genérica, la atención a la cultura de masas y la consiguiente mezcolanza de alta y baja cultura, la configuración de un sujeto débil de la representación, el pastiche y la metaficción (Lozano Mijares 1994: 144).
} 
todo tipo de expresiones culturales que van desde la música jazz hasta las visiones místicas de Rothko y las epifanías terrenales de Pollock y Hopper.

Sin embargo, antes de acercarnos al retrato que Mitre nos ofrece de la ciudad neoyorkina, conviene recordar que el siguiente título del que nos ocuparemos, El paraguas de Manhattan, constituye su último libro poético y se escribe desde el exilio en Estados Unidos, donde fija su residencia después del golpe de estado en Bolivia y del asesinato del líder socialista Marcelo Quiroga Santa Cruz en 1980. Vida y obra del autor se vinculan íntimamente y con extrema coherencia al verse condicionada la materia poética por la distancia y la melancolía del ser desterrado. Mitre reflexionará, en varias ocasiones, acerca del desplazamiento, del sentirse ajeno al lugar que uno habita, de la naturaleza liminal del exiliado y las variables que inciden en su condición de extranjería. Penurias y soledades que, en sus escritos, parecen atenuadas, en contadas ocasiones, por la emoción del descubrimiento de otro mundo, los paseos por ciudades desconocidas, el encuentro con gentes de habla extraña y literaturas en lengua aprendida.

Una vez expuestos los datos biográficos esenciales para comprender algunos de los tópicos que sustentan la escritura que hace Mitre de la urbe, atenderemos a los versos inaugurales del poema inicial, "Ciudad a primera vista", donde se perfila la naturaleza insular del área neoyorkina, contenida y franqueada por "dos ríos como dos brazos / que la ciñen y la estrechan". A lo largo de las piezas poéticas, se genera una ambigua sensación de cautiverio que se vincula con la escasa cantidad de tierra firme, donde el paso o la fuga se ven obstaculizados por nítidas fronteras acuosas. Sin embargo, el contrapunteo retórico que se mantiene durante toda la obra se enraíza en la dual visión del yo lírico que, si por una parte reitera la limitada trayectoria permitida por una tierra estrecha y surcada por el agua, por la otra, celebra el carácter mestizo de los barrios que "a diario amanecen al Pentecostés de las lenguas". Tal amalgama de voces y culturas, capaz de dilatar el perímetro de una ciudad bulliciosa y parlera, ameniza la condena de inmovilismo del poeta.

El rostro más caótico y deshumanizado de la ciudad es descubierto en "Estación Central", donde se pinta un espacio particularmente abarrotado, transitado por "el aguacero de los pasos, / el oleaje de cabelleras / hombros, cejas, labios". Los personajes que se cruzan con el poeta, al que esquivan con velocidad fulminante, aparecen descuartizados en su efímero enfoque sin dejar "ningún trazo en los cambiantes vitrales de la memoria". Nos encontramos, de nuevo, con la advertencia frente a la masa anónima y embrutecida del mundo posmoderno que se sitúa en las antípodas de la clásica multitudine savia. Al observar al poeta golpeado por un interminable 
tráfico de rostros desconocidos, recordamos las palabras de Raymond Williams, para el que "el tránsito no es solamente una técnica, sino una forma de conciencia y una forma de relaciones sociales" (Williams 2001: 365). Esta reflexión acerca de las modalidades de circulación de personas nos aproximan al poema titulado "En el metro", espacio siempre recurrente cuando se habla de la capital americana. En esta composición, se desvelan algunos detalles acerca de la vivencia personal de su autor que sobrevive humildemente mediante "unas clases de español / avaramente pagadas". La experiencia del viaje resulta traumática para el poeta, que se nos muestra titubeante y perdido en el apelotonamiento del subsuelo neoyorkino. La imagen resultante puede asociarse con la intuición de Richard Sennet acerca de la sensorialidad castrada de la metrópolis, donde la planificación urbana evidencia un temor al roce y el orden se identifica con la falta de contacto (Sennet 2007: 23). La proximidad entre los individuos de la ciudad se reduce al choque, al empujón, que lejos de ser un estímulo para la comunicación se concibe como un incentivo para formular una nueva competición. Así, en el poema "Pítica", Nueva York se identifica con una maratón de todos los colores, donde bolivianos, hindúes, texanos, noruegos y africanos se asaltan unos a otros en un extremado grado de aceleración.

Otro aspecto seductor de la poesía de Mitre es la dialéctica que se establece entre dos dimensiones del espacio citadino: la pública y la privada, la exterior y la interior. En "Balada urbana", el poeta nos permite adentrarnos en la intimidad cobijada del "silencio del cuarto", que se contrapone al tumulto de un desbordado espacio callejero. Tal sensibilidad hacia lugares íntimos y diminutos es manifestada por el poeta y crítico francés Gaston Bachelard que estudia la fenomenología poética de espacios pequeños como la guardilla, el cofre o el cajón en contraposición con aquellos inmensos e inabarcables del mundo onírico. El análisis de Bachelard nos resulta pertinente para nuestro estudio dado que, en la obra de Mitre, se reproduce la tajante distinción entre ambos espacios y, mientras la expresión poética aflora en la soledad del dormitorio, tiende a silenciarse en el resto de áreas compartidas. Así, en "Hacia Long Island", nos relata una tentativa de viaje en la que el poeta aparece despojado de toda posibilidad comunicativa, fracasado en su expresión y hundido en un silencio baldío. Frente a las embestidas de la ciudad y el aluvión de rostros, sombras y caminantes de nombre ausente, Mitre se protegerá con su paraguas, objeto enigmático y polifacético, que le permitirá reproducir, en medio de la intemperie callejera, la estructura protegida de la casa y resguardar, por tanto, su discurso poético.

El último aspecto que trataremos del poemario de Mitre, y que nos servirá como puente para deslizarnos hacia la obra de nuestro último poeta, Enrique Lihn, es la evidente predilección por personajes 
solitarios, dolientes y melancólicos. Los seres que recorren el universo poético del boliviano suelen pertenecer a dos categorías, la de los errantes y la de los mutilados, en las que el mismo poeta encuentra su ubicación ontológica. Entre los primeros, es posible identificar al vagabundo "Scott", un nómada de la calle neoyorkina en el que Mitre encuentra una amistosa, aunque fugaz, compañía dado que pasará a engrosar la interminable lista de sus "tantas desapariciones". Otro tipo de errancia, similar a la sufrida por el poeta, es la que define la trayectoria de Pilar Garrido, inmigrante latina a la que, en el poema "Río-Mar", es concedida la voz de la primera persona. Ambas expresiones son, de alguna manera, el trasunto plegado de la del poeta, para el que desdicha e infortunio se entrelazan en una ciudad despiadada y "sacudida por la tempestad / inclemente del dinero".

De otro lado, entre los personajes que hemos convenido en calificar como mutilados, abundan tipos marginales como "La ciega de Union Turnpike", perdida entre la multitud ante la vista paralizada del poeta, o las figuras estoicas de los porteros neoyorkinos que "permanecen en su sitio / plantados en la ardiente / paciencia de su oficio", privados de su libertad de movimiento. En tales poemas, donde "el tono y los ritmos del verso juegan con la cercanía de la prosa" (Muñoz Molina en Mitre 2004: 10), Eduardo Mitre tantea la posibilidad de integrarse en la sociedad real y elige, como vía de acceso, los sustratos más degradados del mundo ficcional e inventado de su poesía. Finalmente, la obra se cierra con la voz del poetanarrador que, haciendo uso de su paraguas, se torna invisible a los ojos de un inmenso escenario en cuyos confines opta por situarse para pasar desapercibido y aguaitar al resto de sus habitantes en un juego de escondites y permanentes camuflajes ${ }^{4}$.

\subsection{Enrique Lihn: voces de margen o arrabal}

Es justamente tal inclinación hacia personajes de ínfima categoría uno de los rasgos que acomuna la poesía de Eduardo Mitre a la del conocido poeta chileno Enrique Lihn (1929-1988). A partir de Manhattan y Pena de extrañamiento, cuyo abordaje teórico realizaremos de manera conjunta, constituyen los dos poemarios que hemos elegido para cerrar nuestro estudio. Ambos estructuran sus contenidos en función de la peregrinatio del sujeto lírico, cuya

\footnotetext{
4 "El paraguas de Manhattan", poema que cierra y da título a la entera composición, constituye una pieza clave para la interpretación del texto de Mitre. El poeta recurre a la metáfora del paraguas para señalar la naturaleza funcional de su escritura que, sometida a un proceso de cosificación, es empleada como escudo o coraza que protege y resguarda al poeta de las embestidas de la ciudad. Por otra parte, la versatilidad del paraguas le permite ocultarse $o$, al menos disimular, la insistente atención con que observa y describe las demás vidas citadinas.
} 
condición itinerante le permite entrar en contacto con escenarios desiguales y variopintos. En la primera de las obras citadas, que se escribe entre febrero y diciembre del año 1978 con la ayuda de una beca otorgada por la Fundación John Simon Guggenheim, junto a la ciudad de Nueva York, se filtran los espacios urbanos de Madrid, Texas y San Francisco. En la segunda, en cambio, publicada en 1986, se refleja la trayectoria del autor en tres ciudades de renombre internacional: Manhattan, Barcelona y Londres.

El espacio literario de sendas obras se ve colmado por la enigmática presencia de seres marginales, que atraen poderosamente la mirada del poeta. Con un enfoque similar al de Mitre, Lihn dedicará el poema "Ciego en el Subway" $(P E)$ a reconstruir la imagen de un misterioso personaje que, sin ver ni ser visto, recorre los túneles subterráneos de la ciudad neoyorkina. Esta seducción por individuos periféricos se evidencia desde la composición inicial del poemario, cuyo primer espacio nombrado es el de "una barraca" donde un vendedor ambulante, contagiado de la repulsión que la urbe manifiesta ante la vejez, ofrece antiguas fotografías de sus antecesores a cambio de algunos centavos. La actitud de desprecio ante las huellas del pasado es extensible a los mismos habitantes de Manhattan, tal y como se demuestra en otro poema, "Vieja en el Subway" $(A P M)$, donde el lector encontrará el retrato envilecido de una anciana decrépita y vagabunda que arrastra sus escasas pertenencias hacia el único hogar que le dispensa la ciudad, "una cama como una fosa / para morir en vida" del Hotel Welfare en Broadway. El chileno, reconociéndose quizás en la exclusión de tales individuos, dará cuenta a lo largo de sus textos de aquellos hábitats invisibles para el resto de la sociedad, recovecos mortíferos destinados al alejamiento y la sepultura de todo tipo de personajes "desclasados, explotados, perseguidos, parados e inservibles".

Al igual que la de sus personajes, la trayectoria del poeta chileno se cumple en los márgenes, tanto materiales como simbólicos, de la ciudad. Al no comprender ni ser comprendido ("Ios hados me caparon del inglés al nacer", confiesa el poeta en algún momento), se enfrenta a una ciudad hermética forjada por códigos ilegibles que le resultan imposibles de descifrar. La reclusión comunicativa de Lihn le conduce hacia el que Michel Foucault va a definir como "pensamiento del afuera" que consiste, justamente, en "experimentar, en el vacío y la indigencia, la presencia del afuera y, ligado a esta presencia, el hecho de que uno está irremediablemente en el afuera del afuera" (Foucault 1988: 34). De ahí, el castigo dantesco, la pena de extrañamiento a la que se ve expuesto el poeta, obligado a circular en un mar de lenguas incomprensibles, un "ruidoso país que nunca rompe su silencio". Esta sensación de desarraigo, le llevará, incluso, a embutir en sus poemas algunas palabras en inglés generando la que el profesor Niall Binns definirá 
como "expresión casi esquizofrénica del bilingüismo forzado de los exiliados" (Binns 1999: 137).

Entre los antihéroes del universo neoyorkino, Lihn reservará un lugar privilegiado para la extravagante bohemia americana que, "sedienta de rouge, aguardiente y drogas", participa con ferocidad en la desbocada neurosis colectiva. El espectáculo desplegado en "La criatura" $(P E)$, poema protagonizado por un grupo de jóvenes heroinómanos, enlaza con la visión nihilista y desesperada del poeta beat Allen Ginsberg que, ya a finales de los años cincuenta, había reaccionado contra la violencia y alienación de sus coetáneos, víctimas de las embaucadoras tentaciones y falsos placeres del orbe moderno:

He visto los mejores cerebros de mi generación destruidos por la locura, famélicos, histéricos, desnudos,

arrastrándose de madrugada por las calles de los negros en busca de un colérico picotazo,

pasotas de cabeza de ángel consumiéndose por la primigenia conexión

celestial con la estrellada dinamo de la maquinaria de la noche. (Ginsberg 1993: 11)

En cierto modo, estos célebres versos del poeta norteamericano serán precursores de la negación y el consiguiente desenmascaramiento de los maravillosos espejismos del mundo capitalista, de los que ya nos prevenía, a finales de siglo, José Martí. Serán numerosos los artistas que, en las últimas décadas de la centuria, dejen de profesar el mito de Manhattan para convertirla en una ciudad descarnada cuyo "presente entrelaza con futuros distópicos" (Sarlo 2009: 161). Entre tales creadores, debemos situar a Enrique Lihn, que no se asombra ante la monumentalidad arquitectónica de la urbe sino que, con la sutil ironía y finísima irreverencia que le caracterizan, se enfrenta a la fisionomía de la ciudad como si de un cuerpo enfermo se tratase, desvelando los síntomas de una endémica patología. A través de un "sujeto descentrado que se disocia y multiplica en un gesto histriónico y teatral" (Foxley 1996: 78), el poeta lleva a cabo una tarea desacralizadora que desinventa las antiguas ficciones para deconstruir el metarrelato que ellas mismas encerraban.

La reacción de Lihn frente a la sacudida emocional que le provoca el espectáculo urbano consiste en indagar acerca de sus aspectos más obscenos y miserables. De poemas como "Pascuas en Nueva York" o "Escombros", cuya materia prima está hecha de restos y despojos, surge una imagen asimilable a la generada por Italo Calvino en un capítulo de su obra Le città invisibili. Entre los distintos modelos urbanos propuestos, se perfila la silueta de "Le città 
continue", diseñadas a imagen y semejanza de la inquietante e infernal ciudad posmoderna. Todos sus elementos forman parte de una única edificación continua y gigantesca, el conocido "villaggio globale" que es descrito como una enorme maquinaria de producir deshechos, una aglomeración interminable de desperdicios acumulados:

Il risultato é questo: piú Leonia espelle roba più ne accumula; le squame del suo passato si saldano in una corazza che non si può togliere; rinnovandosi ogni giorno la città conserva tutta se stessa nella sola forma definitiva: quella delle spazzature d'ieri che s'ammucchiano sulle spazzature dell'altro ieri e di tutti i suoi giorni e anni e lustri ${ }^{5}$. (Calvino 2010: 114)

Tanto el escritor italiano como el chileno coinciden en su versión literaria de la ciudad que, asediada por las sobras de su pasado, observa una frenética remodelación del conglomerado urbano. La ciudad entra en un círculo vicioso en el que, si por una parte se combate la vejez de sus elementos con constantes operaciones quirúrgicas de rejuvenecimiento, por la otra se incrementa la producción de despojos amontonados. Lihn, al hablarnos de un mundo que "se enorgullece de volatilizar el pasado", destaca un rasgo especialmente representativo de la ciudad neoyorkina, esto es, la aversión hacia todo signo de decadencia. La ciudad se emplea infatigablemente en evitar la erosión de sus miembros así como en detener los procesos de corrupción natural de sus construcciones y habitantes. Nos situamos, por tanto, frente al universo que Augé considera paradigmático de la sobremodernidad, cuyas piezas, al verse "prometidas a la individualidad, a lo provisional y a lo efímero, al pasaje" (Augé 1995: 83), resultan privadas de su derecho al envejecimiento. Tal actitud no debiera sorprendernos si recordamos el análisis que Marshall Berman hace del proyecto arquitectónico de remodelación urbanística de Robert Moses, cuyo principal objetivo pretendía cumplir en Manhattan uno de los sueños de la ciencia moderna: "la creación de un sistema en movimiento perpetuo" (Berman 1999: 321).

Es este impetuoso y galopante curso de construcciones y destrucciones el que Lihn logra reproducir en una poesía que se engendra, a su vez, a partir de una entidad poética incierta y cambiante. El sujeto lírico, acezado quizás por las múltiples

\footnotetext{
5 "El resultado es el siguiente: Leonia, cuantas más cosas expele, más acumula; las escamas de su pasado se sueldan en una coraza que no se puede eliminar; renovándose cada día, la ciudad se conserva enteramente a sí misma en su única forma definitiva: aquella de las basuras de ayer que se amontonan sobre las basuras de anteayer y de todos sus días y años y lustros pasados". (La traducción es nuestra).
} 
resurrecciones que observa, asume posiciones variables, inventa distintas máscaras, deambula de una voz a otra sin permitir el estancamiento de su enunciación en ningún punto fermo. Por consiguiente, la labor artística del chileno se vuelve partícipe indiscutible de la experiencia de la modernidad que, siguiendo la célebre definición de Berman, supone concebir

la vida personal y social como una vorágine, encontrarte y encontrar a tu mundo en perpetua desintegración y renovación, conflictos y angustia, ambigüedad y contradicción: formar parte de un mundo en que todo se desvanece en el aire. (Berman 1999: 365)

\section{El mudar de las imágenes en el discurso poético urbano}

El acercamiento propuesto a diversos retratos literarios de la ciudad de Nueva York ha intentado ceñirse a la sugerencia de Gaston Bachelard acerca de la necesidad de captar "el ser de las imágenes en la misma brevedad de su ontología" (Bachelard 1997: 12). Sin embargo, hemos encontrado una dificultad añadida y es que, junto a la fluctuación de la imagen literaria, nos enfrentamos con un referente extratextual urbano que, como hemos comprobado, se define por una naturaleza siempre cambiante. En este sentido, cabe recordar la diferencia que Raymond Williams encuentra entre el tiempo mítico y estancado del espacio rural y el delirante frenesí de los dominios urbanos que, al asociarse con proyectos futuristas y ambiciones de progreso, deben obligarse a permanecer en un estado de perpetua metamorfosis (Williams 2001: 367). De modo que, así como la realidad citadina se ve constantemente afectada por cambios y turbulencias que modifican su forma, trazado y silueta, su presencia en el discurso poético se vuelve, de manera inevitable, vacilante e incierta. La ciudad, como señaló Roland Barthes, deja de ser constitutiva para convertirse en una escritura más, una narración, un discurso a merced de la identidad e imaginación de sus relatores.

Por otra parte, al igual que las imágenes del discurso poético urbano se desvirtúan en continuación, debido a la componente sísmica del paisaje urbano, alterado por constantes derrumbamientos y resurrecciones, las ciudades resultan contagiadas por las mismas mitologías urbanas que las reproducen y que, en cierto modo, participan en su construcción. Esta cadena de mutaciones y procesos de retroalimentación hacen de Nueva York, así como de su correspondiente literario, una realidad proteica y escurridiza, un perpetuum mobile de compleja delimitación. 


\section{Bibliografía}

AUGÉ, Marc (1995): Los no lugares. Espacios del anonimato. Barcelona: Gedisa.

BACHELARD, Gaston (1997): La poética del espacio. México: Fondo de Cultura Económica.

BARTHES, Roland (1993): "Semiología y urbanismo", en La aventura semiológica, pp. 257-266. Barcelona: Paidós.

BERMAN, Marshall (1999): Todo lo sólido se desvanece en el aire: la experiencia de la modernidad. México: Siglo XXI Editores.

BINNS, Niall (1999): "La cultura anglosajona en la poesía chilena del siglo XX". Anales de Literatura Hispanoamericana, núm. 28, pp. 123-139.

CALVINO, Italo (2010): Le cittá invisibili. Milano: Oscar Mondadori.

CAÑAS, Dionisio (1994): El poeta y la ciudad. Nueva York y los escritores hispanos. Madrid: Cátedra.

FOUCAULT, Michel (1988): El pensamiento del afuera. Valencia: Pre-Textos.

FOXLEY, Carmen (1996): "Poesía de Enrique Lihn en el contexto de la modernidad". Revista de Literatura Hispánica, núm. 43, pp. 75-85.

GINSBERG, Allen (1993): Aullido y otros poemas. Madrid: Visor Libros.

KOOLHASS, Rem (2009): Delirio de Nueva York. Un manifiesto retroactivo para Manhattan. Barcelona: Gustavo Gili.

LE CORBUSIER (1985): La ciudad del futuro. Buenos Aires: Ediciones Infinito.

LIHN, Enrique (1979): A partir de Manhattan. Valparaíso: Ganymedes.

- (1986): Pena de extrañamiento. Santiago de Chile: Editorial Sinfronteras.

LOZANO MIJARES, Ma del Pilar (2007): La novela española posmoderna. Madrid: Arco Libros.

LYOTARD, Jean-François (1994): La posmodernidad. Barcelona: Gedisa.

MITRE, Eduardo (2004): El paraguas de Manhattan. Prólogo de Antonio Muñoz Molina. Valencia: Pre-Textos.

SARLO, Beatriz (2009): La ciudad vista. Buenos Aires: Siglo XXI Ediciones.

SENNET, Richard (2007): Carne y piedra. El cuerpo y la ciudad en la civilización occidental. Madrid: Alianza.

SIMMEL, George (1986): "Las grandes urbes y la vida del espíritu", en El individuo y la libertad: ensayos de crítica de la cultura, pp. 247-261. Barcelona: Península.

WILLIAMS, Raymond (2001): El campo y la ciudad. Buenos Aires: Paidós.

ZARDOYA, Concha (1983): Manhattan y otras latitudes. La Coruña: Sociedad de Cultura Valle- Inclán. 